\title{
Isobaric Combustion at a Low Compression Ratio
}

\author{
Aibolat Dyuisenakhmetov, Harsh Goyal, Moez Ben Houidi, and Rafig Babayev \\ King Abdullah University of Science \& Technology \\ Jihad Badra \\ Saudi Aramco \\ Bengt Johansson \\ King Abdullah University of Science \& Technology
}

Copyright @ 2020 SAE International

\begin{abstract}
In a previous study, it was shown that isobaric combustion cycle, achieved by multiple injection strategy, is more favorable than conventional diesel cycle for the double compression expansion engine (DCEE) concept. In spite of lower effective expansion ratio, the indicated efficiencies of isobaric cycles were approximately equal to those of a conventional diesel cycle. Isobaric cycles had lower heat transfer losses and higher exhaust losses which are advantageous for DCEE since additional exhaust energy can be converted into useful work in the expander. In this study, the performance of low-pressure isobaric combustion (IsoL) and high-pressure isobaric combustion (IsoH) in terms of gross indicated efficiency, energy flow distribution and engine-out emissions is compared to the conventional diesel combustion (CDC) but at a relatively lower compression ratio of 11.5. The experiments are conducted in a Volvo D13C500 single-cylinder heavy-duty engine using standard EU diesel fuel. The current study consists of two sets of experiments. In the first set, the effect of exhaust gas recirculation (EGR) is studied at different combustion modes using the same air-fuel ratio obtained from the preceding work. In the second set of experiments, different injection strategies are investigated for IsoL and IsoH combustion at constant and varying load conditions. From the results, it is found that isobaric combustion has similar or higher gross indicated efficiency than those of CDC. The exhaust losses are higher while the heat transfer losses are lower than CDC, which could be beneficial for DCEE concept. For isobaric cases, the $\mathrm{NO}_{x}$ emissions were lower with higher $\mathrm{uHC} / \mathrm{CO} / \mathrm{Soot}$ emissions compared to CDC. From the injection strategy study, it was found that the gross indicated efficiency is highest with three injections i.e. at medium load. The efficiency is lower for both low and high load conditions due to increased exhaust and heat transfer losses, respectively. Also, the gross indicated efficiency is largely unchanged when more than one injection event is executed; however the IsoL yields higher overall emissions as compared to $\mathrm{IsOH}$ combustion.
\end{abstract}

\section{Introduction}

Compression ignition engines operated with conventional diesel fuel are widely used in stationary and transportation energy sectors due to high engine efficiency and reliability advantages. However, attaining the strict emission regulations of nitrogen oxides $\left(\mathrm{NO}_{\mathrm{x}}\right)$, particulate matter (PM), fuel economy and subsequently greenhouse gas (GHG) emissions while retaining high engine efficiency is a challenging task for the engine manufacturers. Around the world, heavy-duty vehicles is largely fueled with diesel fuel and accounts for very high transportcarbon emissions. For example, in the current European automobile market, heavy-duty diesel vehicles constitute for $25 \%$ of the $\mathrm{CO}_{2}$ emissions [ 1 ] and with predicted $45 \%$ increased demand by 2040 , this percentage would likely escalate [2].

In recent years, it is well understood from the existing literature that there are not enough engine efficiency improvements of heavy-duty diesel vehicles. This is potentially due to the lack of major technological breakthrough [3,4]. Advanced combustion concepts such as low-temperature combustion (LTC) diesel $[5,6]$, homogeneous charge compression ignition $(\mathrm{HCCl})[7,8]$, reactivity controlled compression ignition (RCCl) $[9,10]$ and partially premixed charge combustion (PPC) [11-17] has been investigated in detail to improve the thermodynamic efficiency due to reduced heat transfer losses and increased effective expansion ratio. However, the thermodynamic efficiency is not fully converted to brake thermal efficiency (BTE) because of the losses incurred during different cycle components of combustion, gas exchange, and mechanical efficiencies.

To optimize the individual efficiencies, a wide variety of splitcycle engine concept has been investigated ranging from the "series XIV-engine" [18], the compact compression ignition (CCI) engine [19], the Scuderi engine [20], the "CryoPower" engine [21] and the double compression expansion engine (DCEE) [22]. The series XIV-engine comprises of two conventional combustion cylinders and one large low-pressure cylinder. Due to substantial heat losses, the engine efficiency was lower compared to conventional diesel engines. The $\mathrm{CCl}$ engine has an intake cylinder, a combustion cylinder and an exhaust cylinder. The simulations suggested that this concept can result in higher engine efficiency and lower heat transfer losses but the 
actual numbers have not been reported till date. The Scuderi engine utilizes a compressor and expansion cylinder of similar sizes. This concept has reported a high fuel consumption of around $240 \mathrm{~g} / \mathrm{kWh}$ [23]. The "CryoPower" concept consists of an isothermal compressor and recuperator. The simulations reported a very high thermal efficiency of $60 \%$.

Among these combustion technologies, DCEE concept started attracting attention lately. Previous simulation studies [22,2427] suggested that this concept can accomplish a high BTE of $56 \%$ at air-fuel ratio of 3.0 . In this proposed concept, a lowpressure (LP) and a high-pressure (HP) cylinders. The cylinders are set at a phase difference of $180^{\circ}$ i.e. the adjacent cylinders are located at the opposite dead centers. Both these cylinders work on a four-stroke cycle and therefore this is also referred to as 4-4 concept. This configuration is similar to a turbo-charged four-stroke engine such that the turbocharger replaces the LP cylinder of DCEE concept. While the LP cylinder has large displacement volume and works at low pressure to reduce the friction losses, the HP cylinder has a small displacement volume and operates at high pressure to minimize the heat transfer and mechanical losses. The first-stage compression occurs in the LP cylinder and the compressed air is transmitted to a HP cylinder through a charge air cooler (CAC) unit, where the second-stage compression process begins. The events of fuel injection and combustion only occur in HP cylinder which is then followed by a first-stage expansion process. The exhaust gases from the HP cylinder are then fed to the LP cylinder, through the crossover channel, where the second-stage expansion process occurs. The exhaust gases are then pushed into the exhaust manifold and the cycle is completed.

In recent studies [28,29], isobaric combustion cycles were implemented for the DCEE concept and the experiments have been performed only in HP cylinder since it accommodates the combustion event. Instead of utilizing three injectors for achieving isobaric combustion [30], which is a costly option, multiple consecutive injections through a top-mounted single injector were used. This has resulted in similar heat release rate profiles. The results showed that at the same peak cylinder pressures (PCP), the isobaric combustion can achieve similar or higher thermal efficiency with lower $\mathrm{NO}_{x} /$ soot emissions as compared to conventional diesel combustion (CDC).

Previous 1-D simulation results [22] indicated that a low compression ratio of 11.5 is better for DCEE concept as the heat loss occurring during the combustion event can be minimized. This is due to reduced wall surface area to volume ratio of the combustion chamber as compared to higher compression ratio, which can lead to higher thermal efficiency. Therefore in the present study, two isobaric combustion cases: Low isobaric pressure and high isobaric pressure for DCEE concept were studied in HP cylinder and are compared with CDC at a compression ratio of 11.5. The experiments were carried out in a single-cylinder heavy-duty diesel engine connected to an AC motor. The exhaust gas recirculation (EGR) ratio up to $49 \%$ and intake air pressure up to $2.3 \mathrm{bar}$ (absolute) were tested at a fixed fuel mean effective pressure of 17.1 bar. For the two isobaric combustion cycles, the number of injections were also varied (24 ) in order to change the gross IMEP i.e. engine load. Also, at a constant gross IMEP of 6.7 bar (IsoL) and 7.2 bar (IsoH), the number of injections (1-4) were varied. The in-cylinder pressure and exhaust emissions of smoke, $\mathrm{NO}_{x}$, unburnt hydrocarbon
(uHC) and carbon monoxide (CO) were measured for all the operating conditions.

\section{Experimental Setup}

\section{Single-cylinder Engine Facility}

The schematic of the single-cylinder diesel engine used for the isobaric combustion experiments is shown in Figure 1. The Volvo Trucks engine (Model: D13C500) was modified from a conventional 12.8-litre-6-cylinder diesel engine with five of its cylinders deactivated. The engine was connected to an AC motor for the fixed engine speed tests. The engine test cell is connected to a high-pressure air compressor and a pressure regulator is fitted on the intake line to control the air pressure entering the engine, as depicted in Figure 1. The increased intake air boosting will be able to simulate the DCEE concept, in which the boosted air is provided by the LP to HP cylinder. An air flowmeter (Bronkhorst F-106Al-AGD-02-V) was used to measure the air flow rate. The engine intake is connected with an air heater to regulate the air temperature. The intake, exhaust gas recirculation (EGR) and back pressure valves are controlled independently. For all the engine experiments, the back pressure was set to a higher value than the intake pressure (> 0.2 bar) to recirculate the exhaust gases and to maintain a pressure drop, replicating that of a turbocharger. Additionally, there are several pressure sensors and thermocouples installed in the intake and exhaust lines to constantly monitor the pressures and temperatures.

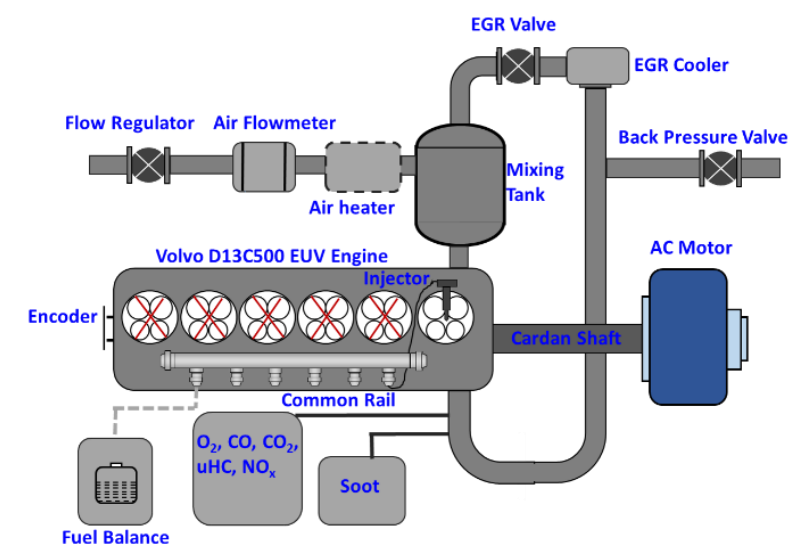

Figure 1. Schematic of the single-cylinder diesel engine setup used for the isobaric combustion experiments

Table 1. Engine specifications

\begin{tabular}{|l|l|}
\hline $\begin{array}{l}\text { Displacement Volume (single } \\
\text { cylinder) }\end{array}$ & $2130 \mathrm{~cm}^{3}$ \\
\hline Stroke & $158 \mathrm{~mm}$ \\
\hline Bore & $131 \mathrm{~mm}$ \\
\hline Connecting Rod & $255 \mathrm{~mm}$ \\
\hline Compression Ratio & $11.5: 1$ \\
\hline Cam/Valve Configuration & $\mathrm{SOHC} / 2$-intake, 2-exhaust \\
\hline Intake Valve Open Timing & $-330^{\circ} \mathrm{CA}$ aTDC \\
\hline Intake Valve Close Timing & $-130^{\circ} \mathrm{CA}$ aTDC \\
\hline Exhaust Valve Open Timing & $180^{\circ} \mathrm{CA}$ aTDC \\
\hline Exhaust Valve Close Timing & $-340^{\circ} \mathrm{CA}$ aTDC \\
\hline
\end{tabular}


Delphi F2E Common-rail (maximum pressure 2700 bar)

The engine has a single-cylinder displacement volume of 2130 $\mathrm{cm}^{3}$ with bore, stroke and connecting rod length as $158 \mathrm{~mm}, 131$ $\mathrm{mm}$ and $255 \mathrm{~mm}$ respectively, as listed in Table 1. The compression ratio of the engine was reduced from standard 17:1 to $11.5: 1$ by replacing the piston and increasing the bowl volume. This is needed for isobaric combustion experiments to limit the PCP during the combustion event in the DCEE concept. The target compression pressure is set by adjusting the intake air pressure. To inject the diesel fuel directly into the combustion chamber, a common-rail fuel system (Delphi F2E) with a solenoid injector was used. The injected fuel mass was measured using a fuel balance system [28]. The LabVIEW fpgabased real-time embedded control system ( $\mathrm{NI} 9038$ CompactRIO) was utilized to drive the engine and record the measured data. A rotary encoder (Leine Linde RSI 503) is mounted on the crankshaft to provide a crank angle resolution of 0.2 crank angle degrees.

\section{Engine Operating Conditions}

In this study, two set of experiments were conducted at fixed engine speed of $1200 \mathrm{rpm}$. The intake air temperature was fixed at $60^{\circ} \mathrm{C}$ while two different intake air pressure (absolute) of 1.7 and 2.3 bar was used. The intake temperature and pressure were increased to match the TDC temperature and pressure of the previous study [26]. Both the coolant and oil temperature were maintained at $85^{\circ} \mathrm{C}$. The common-rail pressure was kept fixed at 1500 bar. The experiments were performed using diesel (Euro 4) fuel with cetane number of 53.8.

Table 2. Engine operating conditions for the first set of experiments

\begin{tabular}{|c|c|c|c|}
\hline & CDC & IsoL & $\mathrm{IsoH}$ \\
\hline Engine speed [rpm] & \multicolumn{3}{|l|}{1200} \\
\hline $\begin{array}{lll}\text { Intake air pressure [bar] } \\
\text { (absolute) }\end{array}$ & \multicolumn{2}{|l|}{1.7} & 2.3 \\
\hline Intake air temperature $\left[{ }^{\circ} \mathrm{C}\right]$ & \multicolumn{3}{|l|}{60} \\
\hline $\begin{array}{l}\text { Coolant (water) temperature } \\
{\left[{ }^{\circ} \mathrm{C}\right]}\end{array}$ & \multicolumn{3}{|l|}{85} \\
\hline Oil temperature $\left[{ }^{\circ} \mathrm{C}\right]$ & \multicolumn{3}{|l|}{85} \\
\hline EGR ratio [\%] & \multicolumn{3}{|c|}{$0, \sim 23, \sim 32, \sim 40, \sim 49$} \\
\hline Common-rail pressure [bar] & \multicolumn{3}{|l|}{1500} \\
\hline Fuel & \multicolumn{3}{|c|}{ CEC RF 0603 Diesel (Euro 4) } \\
\hline Cetane number & \multicolumn{3}{|l|}{53.8} \\
\hline Fuel density at $15^{\circ} \mathrm{C}\left[\mathrm{kg} / \mathrm{m}^{3}\right]$ & \multicolumn{3}{|l|}{835} \\
\hline Low heating value [MJ/kg] & \multicolumn{3}{|l|}{43.2} \\
\hline $\begin{array}{l}\text { Kinematic viscosity at } 40^{\circ} \mathrm{C} \\
{\left[\mathrm{mm}^{2} / \mathrm{s}\right]}\end{array}$ & \multicolumn{3}{|l|}{2.43} \\
\hline Number of injections & 2 & \multicolumn{2}{|l|}{4} \\
\hline $\begin{array}{l}\text { Fuel injection timing } \\
{\left[{ }^{\circ} \mathrm{CA} \text { bTDC }\right]}\end{array}$ & $7,-1$ & $\begin{array}{l}15,2.5,- \\
3.5,-10.5\end{array}$ & $\begin{array}{l}15,2,-3,- \\
9.2\end{array}$ \\
\hline Fuel injection duration $[\mu \mathrm{s}]$ & 200,720 & $\begin{array}{l}200,230 \\
320,530 \\
\end{array}$ & $\begin{array}{l}200,250 \\
310,475\end{array}$ \\
\hline $\begin{array}{l}\text { Total injected fuel mass } \\
\text { [mg/cycle] }\end{array}$ & \multicolumn{3}{|l|}{85} \\
\hline Overall air-fuel ratio $[\lambda]$ & 3 & & 4.1 \\
\hline Fuel MEP [bar] & \multicolumn{3}{|l|}{17.1} \\
\hline
\end{tabular}

Page 3 of 12
In the first set of experiments, the effect of exhaust gas recirculation (EGR) was examined for conventional diesel combustion (CDC), Isobaric $L$ (denoted by IsoL) and Isobaric $\mathrm{H}$ (denoted by $\mathrm{IsoH}$ ) combustion cycles. The EGR ratio calculated using $\mathrm{CO}_{2}$ concentration in the intake and exhaust ( $\mathrm{CO}_{2}^{\text {intake }} / \mathrm{CO}_{2}^{\text {exhaust }}$ ), was tested up to $\sim 49 \%$. CDC can be approximated as an ideal dual cycle (i.e. combination of isobaric and isochoric heat addition). The peak motoring pressure (PMP) and peak cylinder pressure (PCP) of CDC was maintained at 50 and 68 bar respectively, similar with our previous study [28]. This was achieved using an intake air boosting of 1.7 bar-absolute. For IsoL, constant pressure heat addition was maintained at 50 bar with similar intake air pressure as that of CDC. However for $\mathrm{IsoH}$, the heat addition was fixed at 68 bar which represents the PCP of CDC case achieved using intake air pressure of 2.3 barabsolute. The total fuel injected mass of $85 \mathrm{mg} /$ cycle was kept fixed. This corresponds to $\lambda=3$ for CDC and IsoL, and $\lambda=4.1$ for IsoH. The air-fuel ratio for IsoH was higher because of the increased intake air pressure while keeping a fixed injected fuel mass. This fixed air-fuel ratio is consistent with our previous work, conducted with 17-compression ratio piston in the same engine [28]. A total of 12 operating points were studied for the first set of experiments.

Two injection strategy was implemented for CDC. The first (pilot) injection was used to suppress the pressure rise rate during combustion while the second (main) injection was used to control the heat release rate. For IsoL and IsoH combustion cycles, four injections were executed. The injection timings and corresponding durations were adjusted carefully to achieve isobaric combustion. It is to be noted that with increased EGR ratios, the main injection timings were slightly advanced due to decreased charge reactivity for maintaining similar PCP's.

In the second set of experiments (Table 3), the injection strategies of IsoL with PCP of 50 bar and IsoH with PCP of 68 bar was further investigated for two cases. In the first case, the number of injections were increased gradually from two to four to study the effect of engine loads on isobaric combustion. The injection timings and duration for each injection event were kept same as that of first set of experiments. In the second case, the number of injections were varied from one to four for a fixed total injected fuel mass of $85 \mathrm{mg} /$ cycle which corresponds to $\lambda=3$ for IsoL and $\lambda=4.1$ for IsoH. This case is underlined in Table 3 to distinguish it from the first case. For these experiments, no external EGR was implemented. This resulted in a total of 14 operating points for the second set of experiments. It is to be noted that the coefficient of variation (CoV) of IMEP for all the operating conditions is kept below $3 \%$, which represents minimal cycle-to-cycle variations and therefore stable combustion. 
Table 3. Engine operating conditions for the second set of experiments

\begin{tabular}{|c|c|c|c|}
\hline \multirow{2}{*}{\multicolumn{2}{|c|}{\begin{tabular}{|l|} 
\\
Engine speed [rpm]
\end{tabular}}} & IsoL & $\mathrm{IsoH}$ \\
\hline & & 1200 & \\
\hline \multicolumn{2}{|c|}{$\begin{array}{l}\text { Intake air pressure [bar] } \\
\text { (absolute) }\end{array}$} & 1.7 & 2.3 \\
\hline \multicolumn{2}{|c|}{ Intake air temperature $\left[{ }^{\circ} \mathrm{C}\right]$} & \multicolumn{2}{|l|}{60} \\
\hline \multicolumn{2}{|c|}{$\begin{array}{l}\text { Coolant (water) temperature } \\
{\left[{ }^{\circ} \mathrm{C}\right]}\end{array}$} & \multicolumn{2}{|l|}{85} \\
\hline \multicolumn{2}{|c|}{ Oil temperature $\left[{ }^{\circ} \mathrm{C}\right]$} & \multicolumn{2}{|l|}{85} \\
\hline \multicolumn{2}{|c|}{ Common-rail pressure [bar] } & \multicolumn{2}{|l|}{1500} \\
\hline \multicolumn{2}{|l|}{ Fuel } & \multicolumn{2}{|c|}{ CEC RF 0603 Diesel (Euro 4) } \\
\hline \multirow{7}{*}{$\begin{array}{l}\text { Fuel } \\
\text { injection } \\
\text { timing } \\
{\left[{ }^{\circ} \mathrm{CA} \text { bTDC] }\right.}\end{array}$} & \multirow[t]{2}{*}{1 injection } & - & - \\
\hline & & $\underline{\underline{-9}}$ & $\underline{-6}$ \\
\hline & \multirow[t]{2}{*}{2 injections } & $15,2.5$ & 15,2 \\
\hline & & $\underline{0.5,7.5}$ & $\underline{1,-6}$ \\
\hline & \multirow[t]{2}{*}{3 injections } & $15,2.5,3.5$ & $15,2,-3$ \\
\hline & & $\underline{5,-2.5,-10}$ & $\underline{5,-1,-7}$ \\
\hline & 4 injections & $\begin{array}{l}15, \quad 2.5, \quad 3.5,- \\
10.5\end{array}$ & $15,2,-3,-9.2$ \\
\hline \multirow{7}{*}{$\begin{array}{l}\text { Fuel } \\
\text { injection } \\
\text { duration }[\mu s]\end{array}$} & \multirow[t]{2}{*}{1 injection } & - & - \\
\hline & & 810 & 825 \\
\hline & \multirow[t]{2}{*}{2 injections } & 200,230 & 200,250 \\
\hline & & $\underline{330,670}$ & $\underline{320,690}$ \\
\hline & \multirow[t]{2}{*}{3 injections } & $200,230,320$ & $200,250,310$ \\
\hline & & $240,320,545$ & $\underline{210,300,570}$ \\
\hline & 4 injections & $\begin{array}{l}200,230,320 \\
530\end{array}$ & $\begin{array}{l}200,250,310, \\
475\end{array}$ \\
\hline \multicolumn{2}{|c|}{$\begin{array}{l}\text { Total injected fuel mass } \\
\text { [mg/cycle] }\end{array}$} & \multicolumn{2}{|l|}{85} \\
\hline \multicolumn{2}{|c|}{ Overall air-fuel ratio $[\lambda]$} & 3 & 4.1 \\
\hline \multirow{2}{*}{\multicolumn{2}{|c|}{ Fuel MEP [bar] }} & \multicolumn{2}{|l|}{$1.4,8.6,17.1$} \\
\hline & & \multicolumn{2}{|l|}{$\underline{17.1}$} \\
\hline
\end{tabular}

\section{Measurements}

The in-cylinder pressure was recorded for 1000 consecutive cycles via a piezoelectric transducer (AVL GH15DK) coupled with a charge amplifier (AVL FI PIEZO) to convert the charge to voltage signal and consequently pressure. For a given operating condition, the raw pressure data was ensemble-averaged to acquire the in-cylinder pressure traces, indicated mean effective pressure (IMEP) and CoV of IMEP. Also, the rate of heat release (RoHR) was calculated from the in-cylinder pressure traces.

In addition to the in-cylinder pressure measurement, the engineout exhaust emissions of nitrogen oxides ( $\mathrm{NO}_{\mathrm{x}}$ ), unburnt hydrocarbons $(\mathrm{uHC})$ and carbon monoxide $(\mathrm{CO})$ was measured using Horiba Mexa-1700 Motor Exhaust Gas Analyzer. The inlet $\mathrm{CO}_{2}$ concentration was also sampled using this analyzer. The span gases concentration of $\mathrm{CO}, \mathrm{CO}_{2}, \mathrm{O}_{2}, \mathrm{CH}_{4}$ and $\mathrm{NO}$ which are critical in determining the range of exhaust gases are 4932.3 ppm, 18.45 vol\%, 20.00 vol\%, 999 ppm and 8230 ppm, respectively. The soot concentration was measured using AVL Micro Soot Sensor (resolution of $0.01 \mu \mathrm{g} / \mathrm{m}^{3}$ with detection limit of $\left.1 \mu \mathrm{g} / \mathrm{m}^{3}\right)$.

\section{Results and Discussion}

\section{Exhaust Gas Recirculation (EGR) Variation}

\section{In-cylinder Pressure Analysis}

The in-cylinder pressure and rate of heat release rate (RoHR) traces for $\mathrm{CDC}$, IsoL and IsoH combustion at different EGR ratio of $0 \%, 24 \%, 31 \%, 39 \%$ and $49 \%$ is shown in Figure $2 \mathrm{a}$ and $2 \mathrm{~b}$. From the figure, a characteristic difference between CDC and isobaric combustion can be observed i.e. CDC combustion has a single-peak RoHR governed by premixed combustion while the lower-pressure and higher-pressure isobaric combustion has multiple peaks RoHR, and behaves as diffusion flame combustion mode with longer burn duration. These peaks correspond to different injection events. For double-injection based CDC, only single-peak RoHR is visible corresponding to the second-injection because the early first-injection is involved in pre-combustion mixing. Similarly for four injections based isobaric combustion, the first injection is not involved in combustion and therefore resulting in three peaks of RoHR.

With increased levels of exhaust gas recirculation (EGR), the peak RoHR of CDC became higher due to increased ignition delay as EGR decreases the overall charge reactivity. This required advanced second injection timing to maintain the same peak cylinder pressure (PCP). Because of higher premixed combustion with increased EGR ratio, the peak aHRR became narrower indicating faster burning. However for isobaric combustion cases, the increased EGR ratio has no significant influence on RoHR profiles. It is to be noted that for higherpressure isobaric combustion, the injection events need to be coupled closer to account for the in-cylinder pressure and temperature fluctuations during the expansion stroke as compared to lower-pressure isobaric cases. This resulted in significantly higher effective expansion ratio for IsoH combustion meaning more useful work can be extracted from the working fluid. 

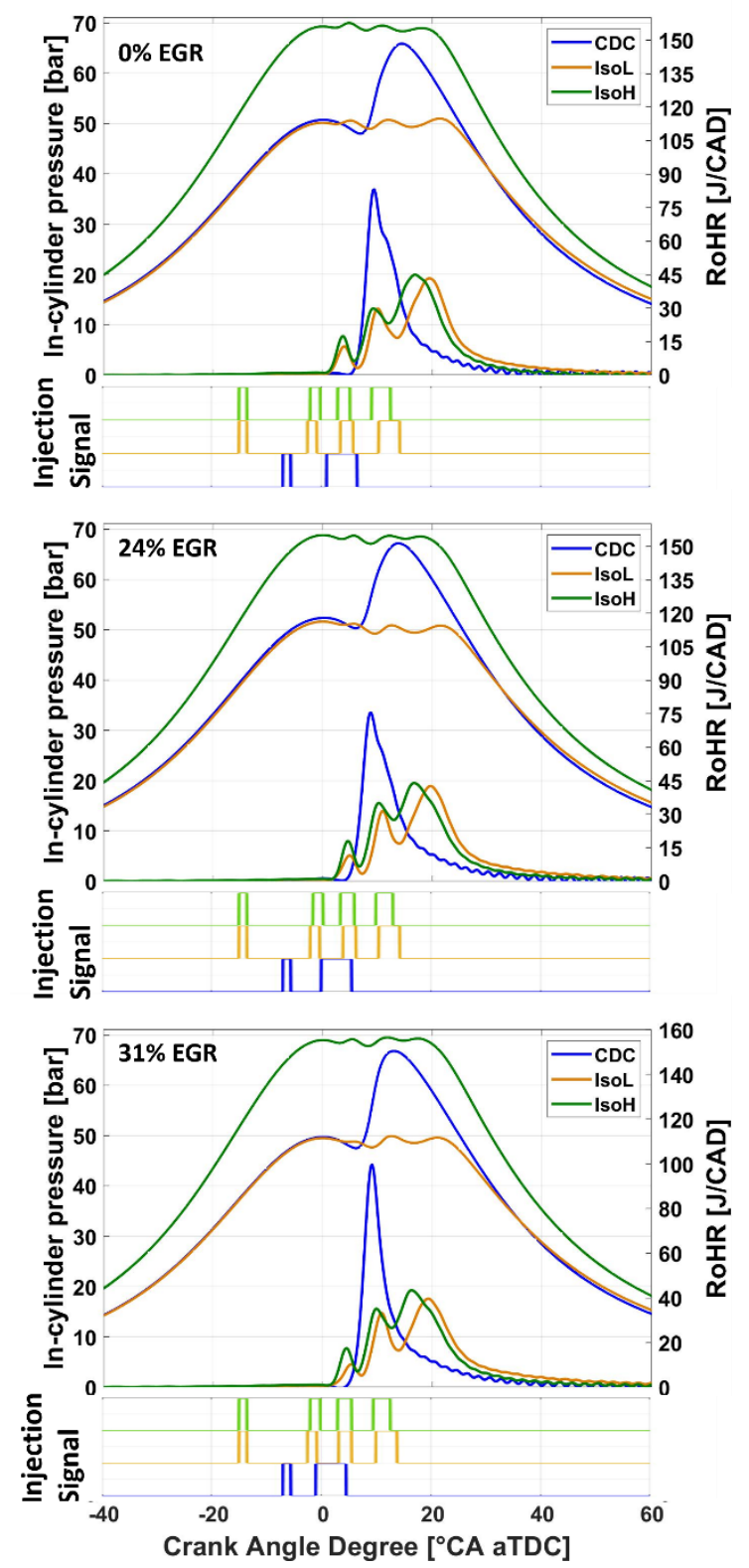

Figure 2a. In-cylinder pressure and rate of heat release (RoHR) traces for $\mathrm{CDC}$, isoL and IsoH combustion at $0 \%, 24 \%$ and $31 \% \mathrm{EGR}$ ratio
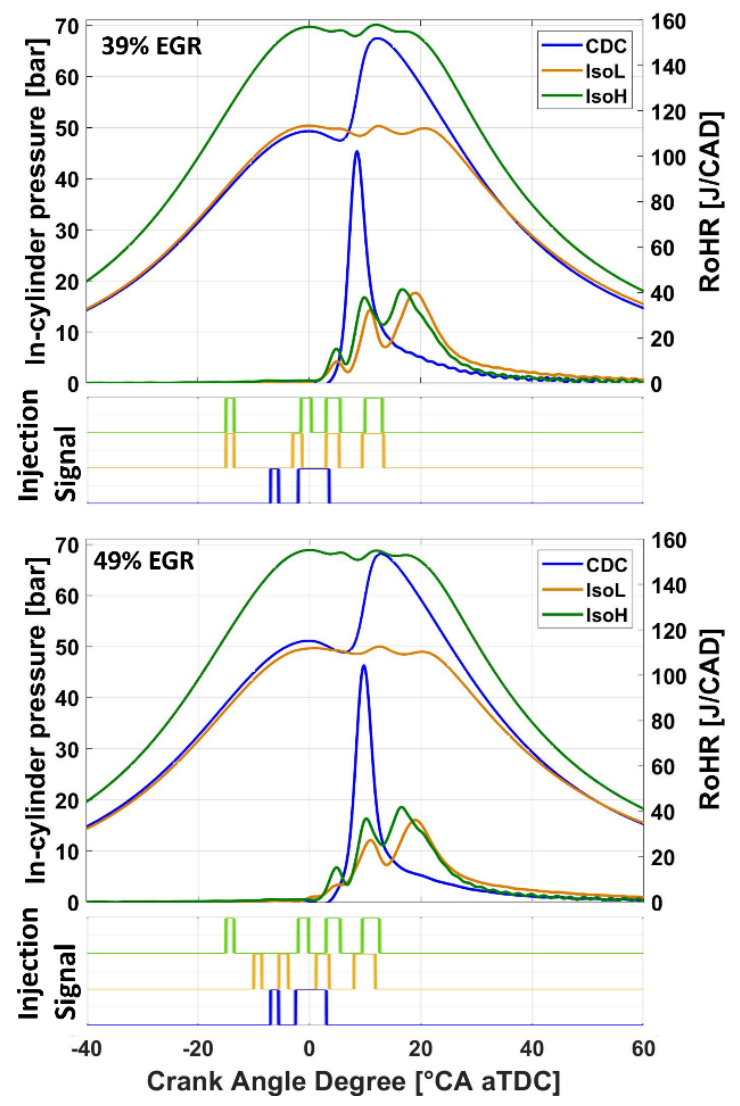

Figure $2 \mathrm{~b}$. In-cylinder pressure and rate of heat release (RoHR) traces for $\mathrm{CDC}$, isoL and IsoH combustion at 39\% and 49\% EGR ratio

\section{Energy Distribution}

The energy distribution of gross indicated efficiency, exhaust losses, heat transfer losses to the walls (i.e. HT losses) and combustion losses for $\mathrm{CDC}$, IsoL and IsoH combustion at different EGR ratio is shown in Figure 3 and 4 . The calculations of gross indicated efficiency and the energy losses are adapted from our previous work $[25,28,29]$. From the figure, it can be seen that IsoH has higher gross indicated efficiency followed by IsoL and CDC for $0 \%$ EGR ratio. With increased levels of EGR, the gross indicated efficiency increases up to $31 \%$ EGR ratio and then almost becomes saturated. For all the EGR cases, IsoH combustion has over $\sim 1-2 \%$ points higher efficiency than CDC combustion while the IsoL combustion exhibits the least efficiency.

It is found that the exhaust losses for isobaric combustion i.e. $\sim 4 \%$ point for IsoL and $\sim 5 \%$ point for IsoH. is higher than those of CDC. This is because of longer combustion duration (Figure $2 \mathrm{a}$ and $2 \mathrm{~b}$ ) which resulted in lower effective expansion ratio for IsoL and IsoH combustion compared to CDC. This can be also explained by higher exhaust temperature observed for isobaric combustion compared to CDC. For a fixed combustion mode, the increased EGR ratio resulted in increased exhaust enthalpy and therefore lead to higher exhaust losses. The heat transfer losses follows an opposite trend to that of exhaust losses i.e. both the isobaric combustion cases has lower heat transfer losses than those of CDC due to slower burning which has resulted in overall lower peak in-cylinder temperature, as shown 
in Figure 5. Increased levels of EGR resulted in lower heat transfer losses because of reduced flame temperature associated with higher charge dilution.

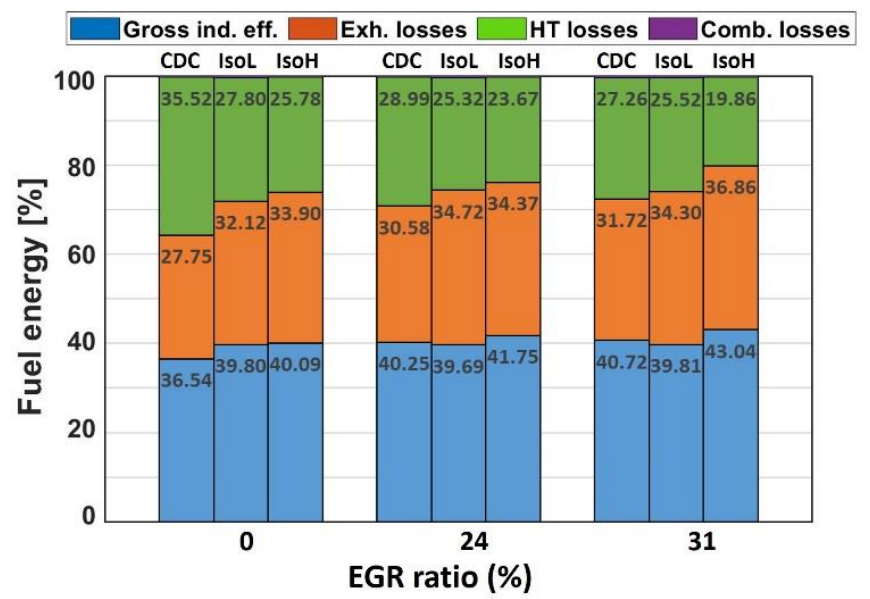

Figure 3. The energy distribution of gross indicated efficiency, exhaust losses, heat transfer losses and combustion losses for CDC, isoL and IsoH combustion at $0 \%, 24 \%$ and $31 \%$ EGR ratio

Irrespective of different EGR ratios, the gross indicated efficiency is about $\sim 3-4 \%$ points lower, exhaust losses are about $\sim 4-5 \%$ points higher and heat transfer losses are 3-4\% points lower as compared to our previous work conducted at 17 compression ratio [28]. The reduced heat transfer losses to the walls as compared to increased exhaust losses is more beneficial for double compression expansion engine (DCEE) concept because the exhaust energy can be recovered using an additional expander unit.

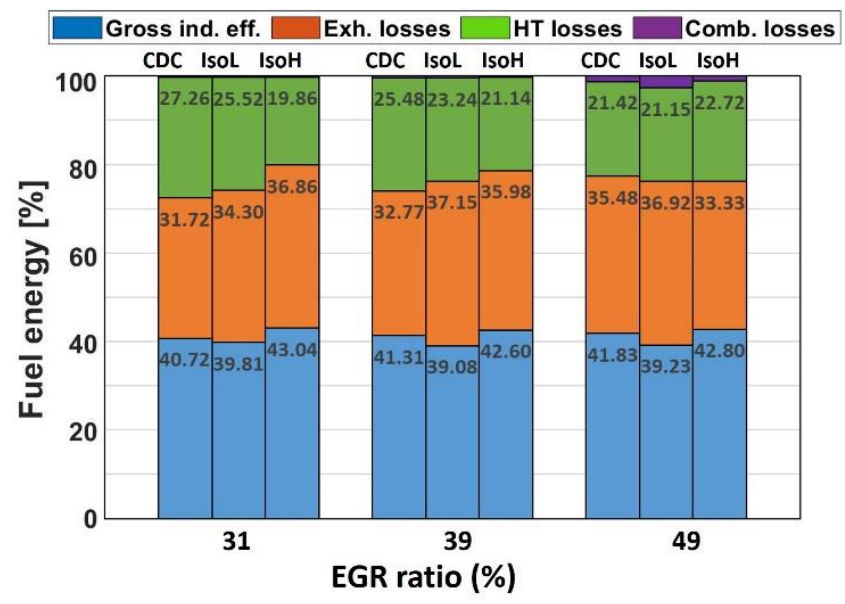

Figure 4. The energy distribution of gross indicated efficiency, exhaust losses, heat transfer losses and combustion losses for CDC, isoL and IsoH combustion at $31 \%, 39 \%$ and $49 \%$ EGR ratio

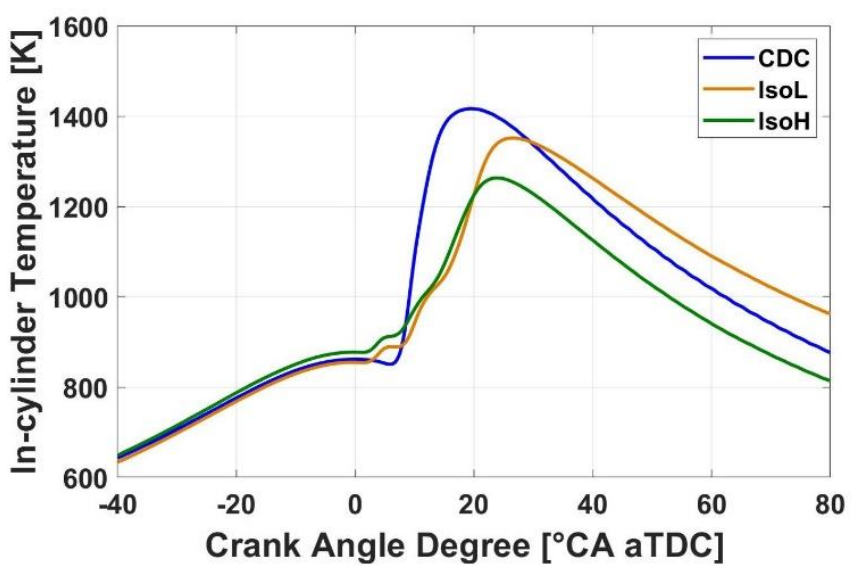

Figure 5. The in-cylinder temperature for $\mathrm{CDC}$, iso $\mathrm{L}$ and IsoH combustion at $0 \% \mathrm{EGR}$ ratio

\section{Emissions}

Figure 6 shows the gross indicated specific emissions of unburnt hydrocarbon ( $\mathrm{UHC}$ ), carbon monoxide (CO), oxides of nitrogen $\left(\mathrm{NO}_{\mathrm{x}}\right)$, and soot concentration in the exhaust for $\mathrm{CDC}$, IsoL and IsoH combustion at different EGR ratios. The $\mathrm{UHC}$ emissions is higher for isobaric cases as compared to CDC for all the EGR ratio. This is because of late injection timing for isobaric cases produce locally fuel-rich mixture zones which results in incomplete combustion. However, the $\mathrm{CO}$ emissions are comparable for all the combustion modes except with the higher EGR ratio, when $\mathrm{CO}$ emissions become very high because of lower reaction temperature and oxidation rate.

The soot emissions are very similar for IsoH and CDC but very high for isoL. This can be explained by a lower air-fuel ratio required for IsoL which resulted in lower oxygen concentration and therefore poor soot oxidation. With higher EGR ratio, the soot concentration further increases particularly for IsoL combustion because of the relatively low reaction temperatures, similar to the trend of $\mathrm{uHC} / \mathrm{CO}$ emissions. This is found to be consistent with previous optical studies [31, 32] where the fuel from late third and fourth injection is being injected into the existing flames, resulting in locally fuel-rich mixture zones and therefore high soot production. A conventional soot-NOx tradeoff is clearly observed here. The increased levels of EGR resulted in lower flame temperature and therefore decreasing thermal NO formation. Compared to CDC, the $\mathrm{NO}_{x}$ emission levels are very similar except with no EGR case when IsoL and IsoH have lower $\mathrm{NO}_{x}$ emissions. This is due to lower in-cylinder temperature for isobaric combustion cases, as seen in figure 5 . 

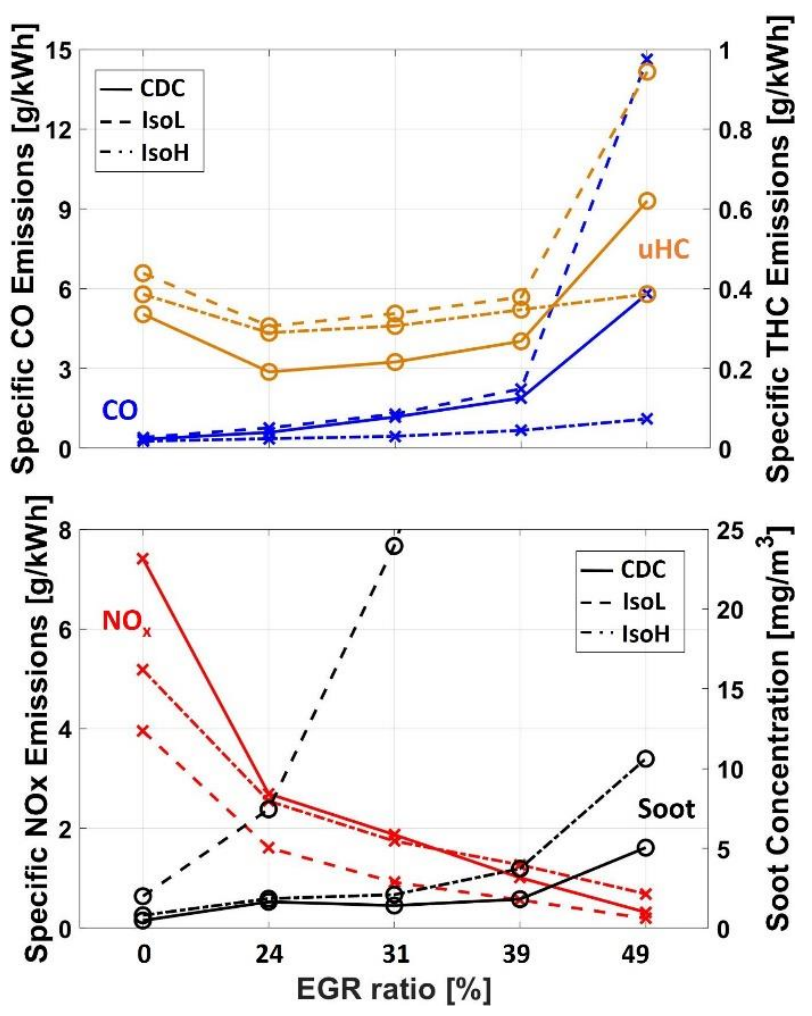

Figure 6. The engine-out emissions of unburnt hydrocarbon ( $\mathrm{UHC}$ ), carbon monoxide (CO), oxides of nitrogen (NO) and soot concentration for iso $\mathrm{L}$ and IsoH combustion at $0 \%, 24 \%, 31 \%, 39 \%$ and $49 \%$ EGR ratio

\section{Number of Injections - Load Variation}

\section{In-cylinder Pressure Analysis}

Figure 7 shows the in-cylinder pressure and RoHR traces for IsoL (top row) and IsoH (bottom row) combustion conditions. In each plot, the data is shown for two, three and four injections which corresponds to gross IMEP (load conditions) of 0.1, 2.5 and 6.7 bar for IsoL and $0.15,3.6$ and 7.2 bar for IsoH. The injection timings, duration and other operating conditions are listed in Table 3.

To achieve the isobaric combustion, the PCP is kept constant at 50 bar for IsoL and 68 bar for IsoH by carefully controlling the injection timings and corresponding duration, and thereby monitoring the RoHR. This means that the rate at which the energy is added to the working gas is similar to the removal rate which leads to useful work along with heat transfer losses by piston movement. To achieve the low-load condition, the isobaric combustion is not evident because of limited fuel injected mass and this resulted in a small peak of RoHR. However, as the load is increased, the peak RoHR shows an increasing trend with retarded combustion phasing.
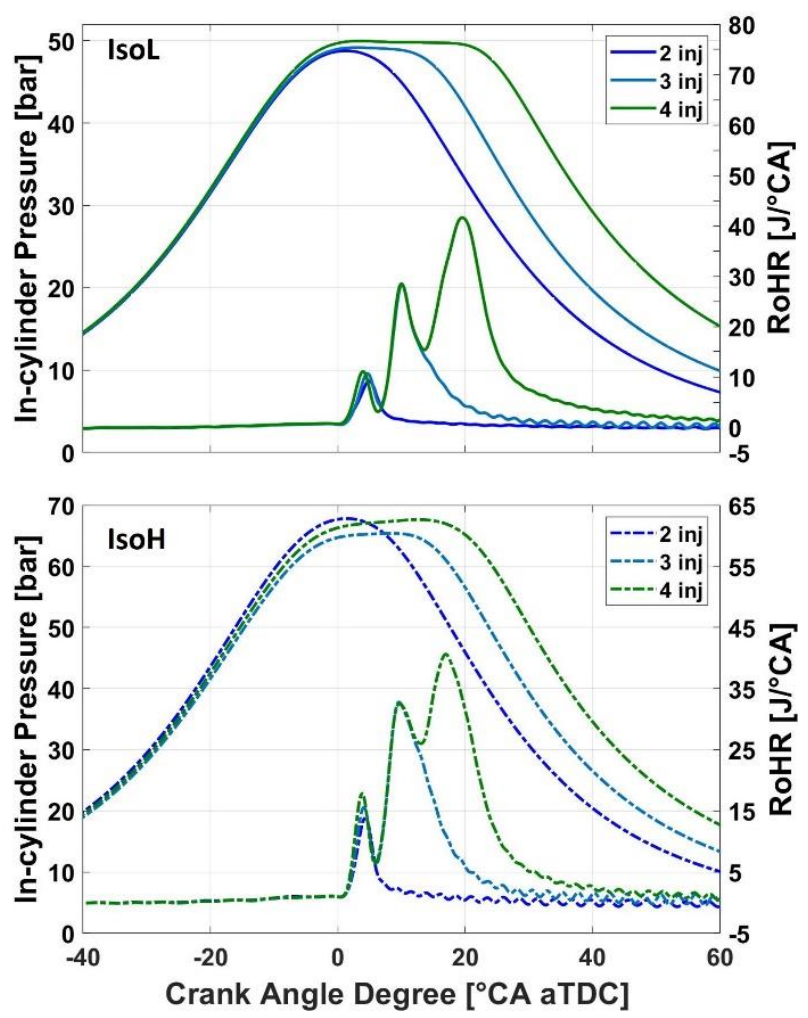

Figure 7. In-cylinder pressure and rate of heat release (RoHR) traces for iso $\mathrm{L}$ and IsoH combustion at varying loads

\section{Energy Distribution}

Figure 8 shows the energy distribution of gross indicated efficiency, exhaust losses, heat transfer losses and combustion losses for different injection strategy corresponding to varying load conditions of IsoL and IsoH. From the figure, it can be seen that the gross indicated efficiency is very low for double-injection strategy and then it rises to a peak value and then decreases with increased number of injections for IsoL combustion. However, for IsoH combustion, the gross indicated efficiency follows an increasing trend with more injections. The peak efficiency of $42.5 \%$ is achieved for IsoL using three injections and $\mathrm{IsOH}$ with four injections possibly due to optimized combustion phasing. The exhaust energy losses increases with fewer injections for both the isobaric combustion cases. The heat transfer losses decreases with fewer injection events except for the double-injection case of IsoH. This can be explained with the assistance of in-cylinder temperature plots in Figure 9. It was found that the peak in-cylinder temperature is correlated with the heat transfer losses; however, it is not clear why the double-injection strategy of IsoH combustion results in high exhaust losses when the peak in-cylinder temperature is very low. The combustion losses are found to be minimal for three and four injections as compared to single-injection strategy. Overall, the indicated efficiency is highest for three injections i.e. at medium load. The efficiency is lower for both low and high load conditions due to increased exhaust and heat transfer losses, respectively. 


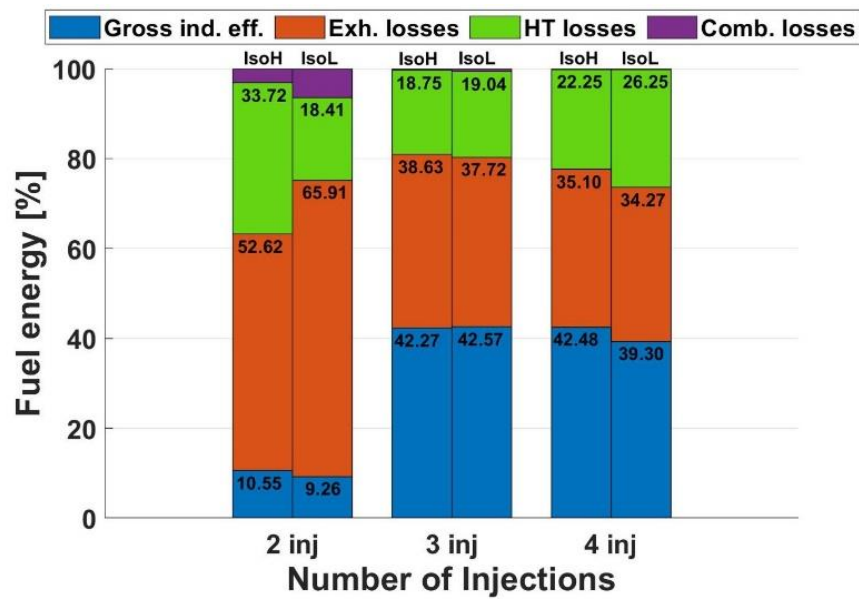

Figure 8. The energy distribution of gross indicated efficiency, exhaust losses, heat transfer losses and combustion losses for isoL and IsoH combustion at varying load

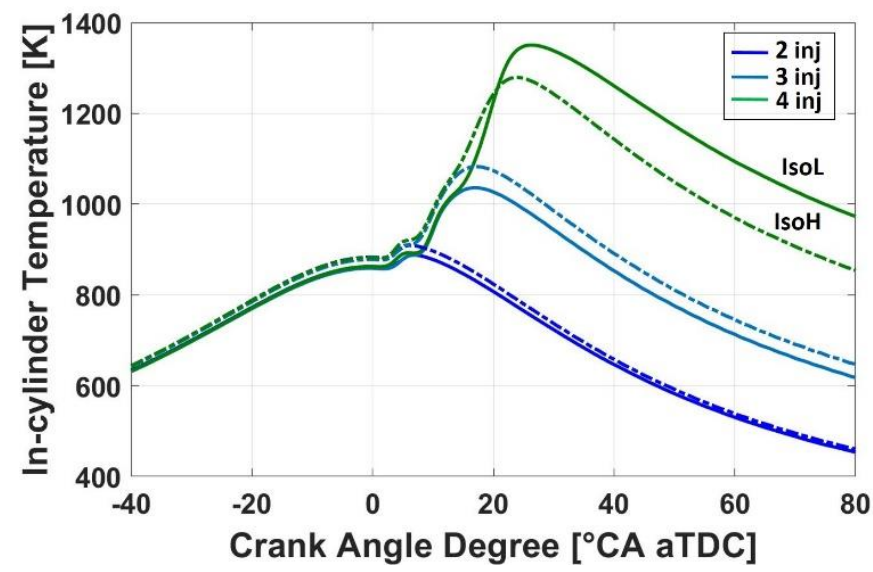

Figure 9. The in-cylinder temperature for isoL and $\mathrm{IsoH}$ combustion at varying load

\section{Emissions}

The gross indicated specific emissions of $\mathrm{uHC}, \mathrm{CO}$ and $\mathrm{NO}_{x}$ and soot concentration in the exhaust for different injections representing varying load conditions, is illustrated in Figure 10. For a given isobaric combustion condition, it can be seen that the $\mathrm{UHC}$ and $\mathrm{CO}$ emissions follow a decreasing trend with increased number of injections, which is due to increased combustion temperature (Figure 9). The uHC emissions are found to be maximum for the first-injection and with subsequent injections and increased combustion temperature, they are burned off to a minimum level. Similarly, because of lower combustion temperature for lesser number of injections, the fuel is not oxidized completely resulting in higher $\mathrm{CO}$ emissions. The lower temperature reaction for lesser number of injections also caused almost linear decrease in thermal NO formation, which led to lower $\mathrm{NO}_{x}$ formation. For each injection event, although the amount of fuel injected is different, still it results in almost similar $\mathrm{NO}_{x}$ formation. The soot emissions follows an opposite trend as that of $\mathrm{NO}_{\mathrm{x}}$ emissions i.e. the soot formation is very low for lower injections and with increased number of injections, the soot formation becomes higher due to the formation of locally fuel-rich pockets. It can be seen from Figure 9 that the Page 8 of 12 combustion temperature with increased injection events is not high enough for soot oxidation and therefore resulting in poor air-fuel mixing and hence higher soot concentration in the exhaust.

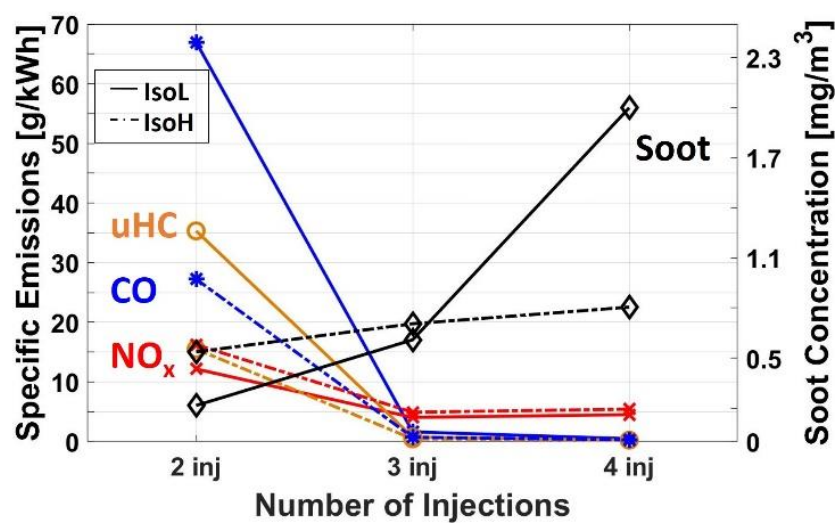

Figure 10. The engine-out emissions of unburnt hydrocarbon ( $\mathrm{UHC}$ ), carbon monoxide (CO), oxides of nitrogen (NO) and soot concentration for isoL and IsoH combustion at varying load

\section{Number of Injections - Constant Load}

\section{In-cylinder Pressure Analysis}
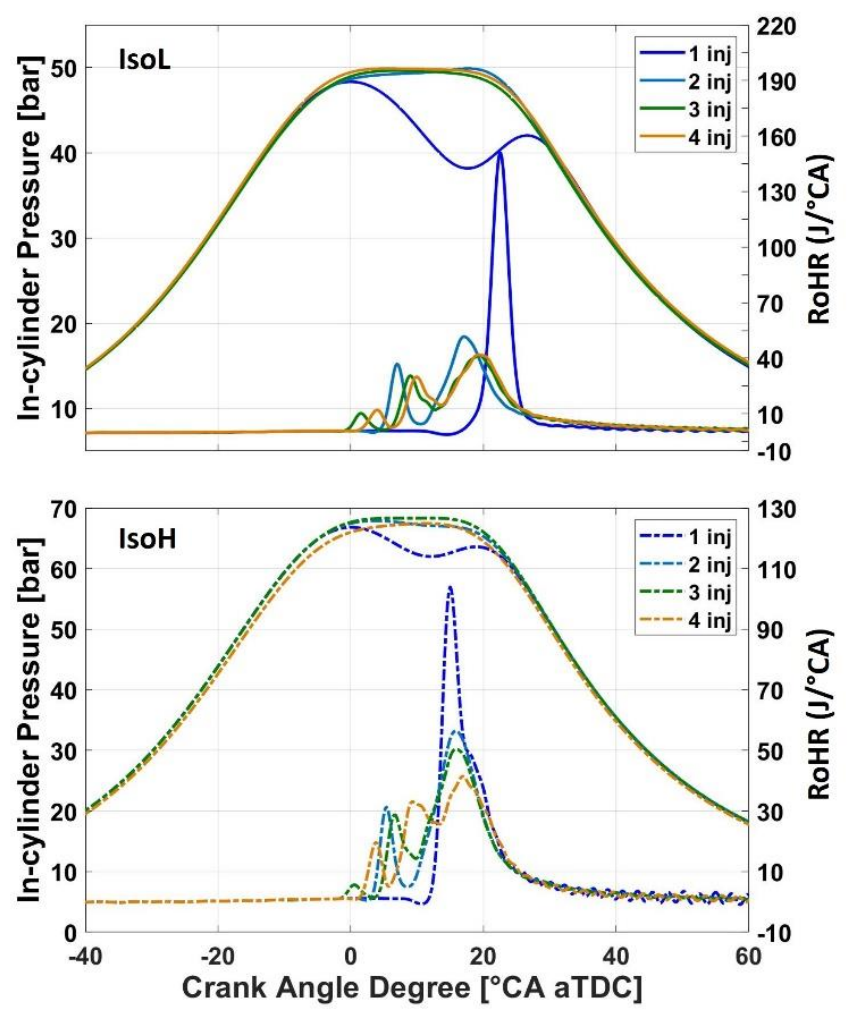

Figure 11. In-cylinder pressure and rate of heat release (RoHR) traces for isoL and IsoH combustion at constant load

The in-cylinder pressure and RoHR traces are plotted for four different injection strategies of IsoL (top row) and IsoH (bottom row) at constant gross IMEP of $6.7 \mathrm{bar}$ (IsoL) and $7.2 \mathrm{bar}$ (IsoH) 
in Figure 11. The overall air-fuel equivalence ratio is kept constant for IsoL $(\lambda=3)$ and IsoH $(\lambda=4.1)$ by varying the injected fuel mass per injection event. From the figure, it is clear that when the number of injections are lowered to single-injection condition, the pressure traces do not exhibit isobaric combustion characteristics. In particular, for single-injection strategy, a very late injection timing was selected for both the isobaric combustion cases such that the peak cylinder pressure (PCP) matches the peak motoring pressure (PMP) of 50 bar. It is to be noted that each injection event corresponds to a local maxima in aHRR trace except for the four-injection strategy where only three peaks corresponding to last three injections are visible. This is because retarding the first-injection timing resulted in a higher desired PCP. With increased number of injections, the combustion process approached towards isobaric combustion which leads to a lower global maxima (final peak) of aHRR.

\section{Energy Distribution}

Figure 12 shows the energy distribution of gross indicated efficiency, exhaust losses, heat transfer losses and combustion losses as a fraction of the total fuel energy for different injection strategy of IsoL and IsoH at fixed load condition. It can be seen that for IsoL combustion, the gross indicated efficiency is least for single-injection which then rises to a peak value for secondinjection and then follows a decreasing trend. However for IsoL combustion, the gross indicated efficiency increases with increased number of injections. This can be explained from the RoHR traces in Figure 11 such that the advanced combustion phasing leads to higher gross indicated efficiency and viceversa. The gradual increase in exhaust losses with decreased injections could be due to a retarded combustion phasing resulting in lower effective expansion ratio; however, with an exception of single-injection strategy. The increased exhaust losses of isobaric combustion from the present study would not be an issue for DCEE concept because of the expander unit in which the second-stage exhaust energy can be further expanded and therefore considerably reducing the exhaust losses. This need further verification by performing a 1-D numerical simulation with the experimental data obtained from this study. On the contrary, the heat transfer losses decreases with fewer injections, except for the first-injection case for which the heat transfer losses are significantly higher. To understand this behavior, the in-cylinder temperature are plotted in Figure 13. It can be seen that for a fixed isobaric combustion, peak incylinder temperature is similar for various injection strategies unlike the varying load condition (Figure 9). However, the major differences exists in in-cylinder temperature close to TDC because of different injection timings. Compared to IsoL, IsoH combustion leads to lower peak in-cylinder temperature which also remains low during the expansion stroke and therefore resulting in lower temperature gradient at the combustion chamber walls and therefore low heat transfer losses. Similar to the varying load condition (Figure 8), the combustion losses are found to be negligible for higher number of injections as compared to fewer injection. Except for the first injection, the gross indicated efficiency and all other energy losses are found to be largely unchanged with increased number of injections.

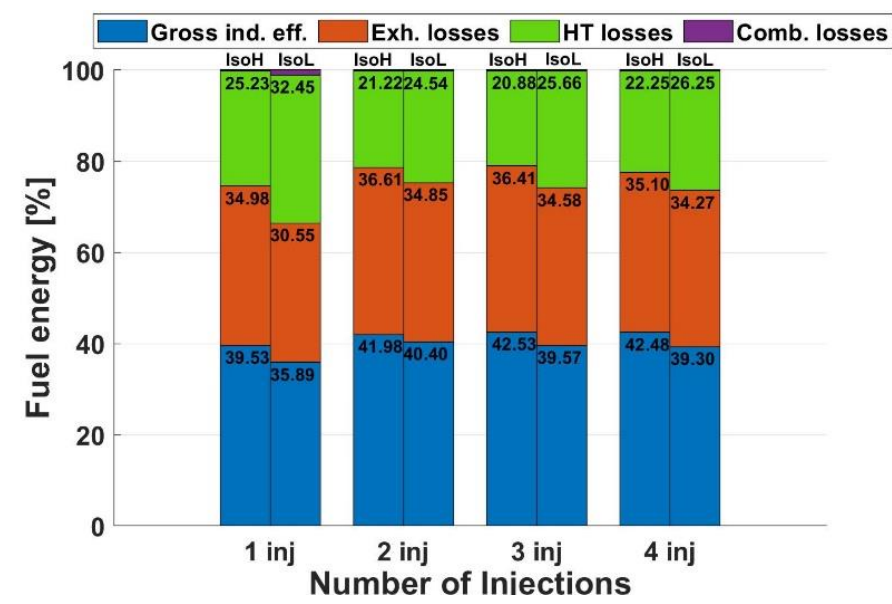

Figure 12. The energy distribution of gross indicated efficiency, exhaust losses, heat transfer losses and combustion losses for isoL and IsoH combustion at constant load

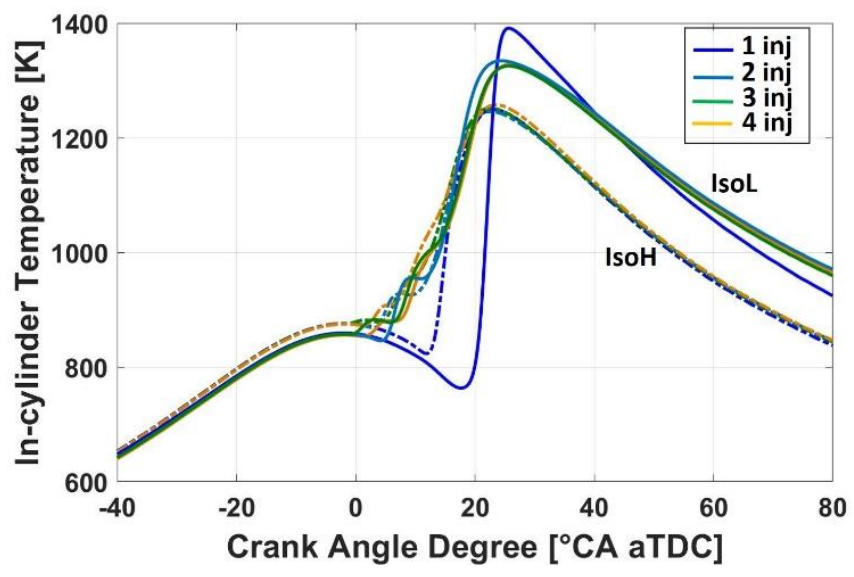

Figure 13. In-cylinder temperature for iso $\mathrm{L}$ and $\mathrm{IsoH}$ combustion at constant load

\section{Emissions}

Figure 14 shows the gross indicated specific emissions of $\mathrm{UHC}$ $\mathrm{CO}$ and $\mathrm{NO}_{x}$, and soot concentration in the exhaust for IsoL and $\mathrm{IsoH}$ at constant load condition. The $\mathrm{uHC}$ and $\mathrm{CO}$ emissions does not vary significantly with different injection-strategy except for the first-injection case for which the combustion event happened late and therefore inadequate time to burn the remaining hydrocarbon in the fuel, resulting in locally fuel-rich mixtures and consequently higher $\mathrm{uHC}$ and $\mathrm{CO}$ concentration in the exhaust. For iso $\mathrm{H}$ combustion, the $\mathrm{NO}_{x}$ emissions remain almost constant despite the number of injections. However, for isoL combustion, the $\mathrm{NO}_{\mathrm{x}}$ emissions follow a decreasing trend with increased number of injections. This is not very clear from figure 13 as the peak in-cylinder temperature is found to be similar for multiple injection strategy of isobaric combustion except for single-injection case. However, it is thought that the thermal NO formation was reduced due to limiting mixing time with increased number of injections. A conventional soot-NOx trade-off can be seen such that the soot emissions increases with increased number of injections irrespective of different isobaric combustion conditions. The observed trends could be explained by locally richer fuel-air mixtures for the higher 
injection strategy to maintain a constant net IMEP. The overall emissions for IsoL is found to be higher than that of $\mathrm{IsoH}$ combustion because of lower air fuel ratio required to maintain the constant load.

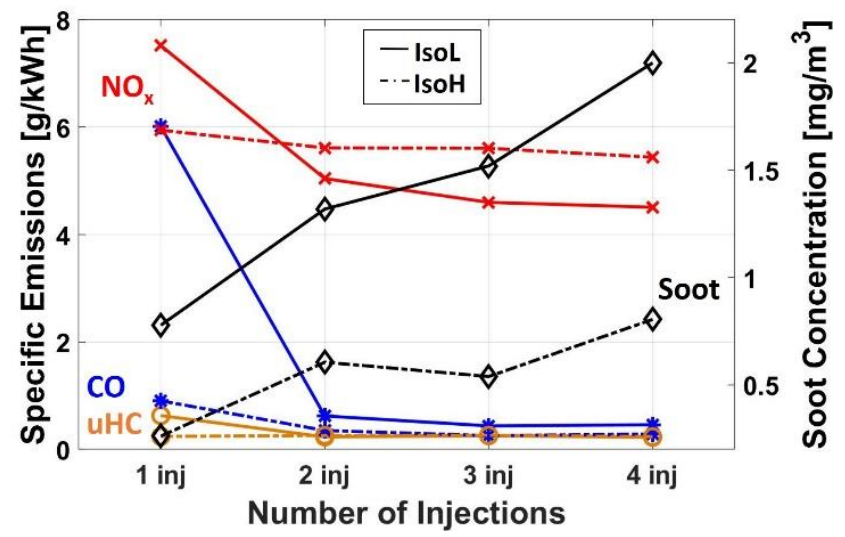

Figure 14. The engine-out emissions of unburnt hydrocarbon ( $\mathrm{uHC}$ ), carbon monoxide (CO), oxides of nitrogen (NO) and soot concentration for isoL and IsoH combustion at constant load

\section{Conclusions}

The effect of EGR and different injection strategies coupled with varying load conditions on two isobaric combustion conditions has been investigated in a Volvo D13C500 single-cylinder heavy-duty engine. The EGR ratio was varied from 0 to $49 \%$ at fixed fuel mean effective pressure of 17.1 bar while the number of injections were increased up to four at fixed and varying load condition, which has led to the following major conclusions.

1. Low-pressure isobaric and high-pressure isobaric combustion has similar or higher gross indicated efficiency than those of conventional diesel combustion at different levels of EGR.

2. Isobaric combustion cases resulted in lower heat transfer losses compared to CDC thanks to the reduced in-cylinder temperature; however, higher exhaust losses due to reduced effective expansion ratio.

3. $\mathrm{uHC} / \mathrm{CO} / \mathrm{Soot}$ emissions are higher for isobaric cases as compared to diesel combustion because of late injection strategy, which resulted in lower flame temperature and oxidation rate. However, the $\mathrm{NO}_{x}$ emissions are lower for isobaric combustion than those of CDC.

4. With increased EGR dilution, irrespective of the combustion modes, the $\mathrm{uHC} / \mathrm{CO} / \mathrm{emissions}$ follows an increasing trend with decreased $\mathrm{NO}_{x}$ emissions for isobaric combustion than those of CDC due to lower flame temperature.

5. By gradually increasing the number of injection, the engine load is varied. The gross indicated efficiency was found to be maximum at medium load point with three injections due to optimized heat transfer and exhaust losses.
6. With increased number of injections at varying load condition, the $\mathrm{uHC} / \mathrm{CO} / \mathrm{NO}_{x}$ emissions follow a decreasing trend with higher soot emissions.

7. With increased number of injections at constant load of 6.7 and 7.2 bar gross IMEP for IsoL and IsoH combustion respectively, the gross indicated efficiency is largely unchanged. However, the overall efficiency of IsoL is found to be higher as compared to IsoH combustion.

8. Overall, the isobaric combustion achieved using multiple injection strategy can be more suitable for the double compression expansion engine concept, compared to conventional diesel combustion.

\section{Future work}

Similar set of isobaric combustion experiments will be performed in the future but at much higher peak motoring and peak cylinder pressures. Operating at high peak pressures of 250-300 bar requires robust mechanical design and expectedly higher friction losses compared to conventional four-stroke diesel engine. However, higher load conditions can be achieved with higher peak in-cylinder pressure and acceptable mechanical efficiency.

\section{References}

1. Strategy for Reducing Heavy-Duty Vehicles' Fuel Consumption and $\mathrm{CO} 2$ Emissions, http://ec.europa.eu/clima/policies/transport/vehicles/he avy/docs/com_285_2014_en.pdf, 2014.

2. The Outlook for Energy: A View to 2040, 2016.

3. Muncrief, R. and Sharpe, B., "Overview of the Heavyduty Vehicle Market and CO2 Emissions in the European Union," 2015.

4. http://s04.static-shell.com/content/dam/shell-new/local/ country/deu/downloads/pdf/publications-

2010truckstudyfull.pdf.

5. Kook, S., Bae, C., Miles, P.C., Choi, D., and Pickett, L.M., "The Influence of Charge Dilution and Injection Timing on Low-temperature Diesel Combustion and Emissions," SAE Technical Paper 2005-01-3837, 2005, doi:10.4271/2005-01-3837.

6. Noehre, C; Andersson, M; Johansson, B; Hultqvist, A., "Characterization of Partially Premixed Combustion," SAE Technical Paper 2006-01-3412, 2006, doi:10.4271/2006-01-3412.

7. Maurya, R.K. and Agarwal, A.K., "Combustion and Emission Behavior of Ethanol Fuelled Homogeneous Charge Compression Ignition $(\mathrm{HCCl})$ Engine," SAE Technical Paper 2008-28-0064, 2008, doi:10.4271/2008-28-0064.

8. Christensen, M., Johansson, B., and Einewall, P., "Homogeneous Charge Compression Ignition ( $\mathrm{HCCl})$ using Isooctane, Ethanol and Natural Gas - A Comparison with Spark Ignition Operation," SAE Technical Paper 972874, 1997, doi:10.4271/972874.

9. Splitter, D., Hanson, R., Kokjohn, S., and Reitz, R.D., "Reactivity Controlled Compression Ignition (RCCI) Heavy-duty Engine Operation at Mid-and High-loads with Conventional and Alternative Fuels," SAE Technical Paper 2011-01-0363, 2011, 
doi:10.4271/2011-01-0363.

10. Kokjohn, S., Reitz, R.D., Splitter, D., and Musculus, M., "Investigation of Fuel Reactivity Stratification for Controlling PCI Heat-release Rates using High-speed Chemiluminescence Imaging and Fuel Tracer Fluorescence," SAE Int. J. Engines 5(2):2012-01-0375, 2012, doi:10.4271/2012-01-0375.

11. Kalghatgi, G.T., Risberg, P., and Ångström, H.-E., "Advantages of Fuels with High Resistance to Autoignition in Late-injection, Low-temperature, Compression Ignition Combustion," SAE Technical Paper 2006-01-3385, 2006, doi:10.4271/2006-01-3385.

12. Kalghatgi, G.T., Risberg, P., and Angstrom, H.-E., "Partially Pre-mixed Auto-ignition of Gasoline to Attain Low Smoke and Low NOx at High Load in a Compression Ignition Engine and Comparison with a Diesel Fuel," SAE Technical Paper 2007-01-0006, 2007, doi:10.4271/2007-01-0006.

13. Goyal, H., Kook, S., Hawkes, E., Chan, Q.N., Padala, S., and Ikeda, Y., "Influence of Engine Speed on Gasoline Compression Ignition (GCl) Combustion in a Single-cylinder Light-duty Diesel Engine," SAE Technical Paper 2017-01-0742, 2017, doi:10.4271/2017-01-0742.

14. Goyal, H., Kook, S., and Ikeda, Y., "The Influence of Fuel Ignition Quality and First Injection Proportion on Gasoline Compression Ignition (GCl) Combustion in a Small-bore Engine," Fuel 235:1207-1215, 2019, doi:10.1016/j.fuel.2018.08.090.

15. Goyal, H. and Kook, S., "Ignition Process of Gasoline Compression Ignition (GCl) Combustion in a Small-bore Optical Engine," Fuel 256:115844, 2019, doi:10.1016/j.fuel.2019.115844.

16. Goyal, H., Zhang, Y., Kook, S., Kim, K.S.., and Kweon, C.-B., "Low- to High-temperature Reaction Transition in a Small-bore Optical Gasoline Compression Ignition (GCI) Engine," SAE Int. J. Engines 12(5), 2019, doi:10.4271/03-12-05-0031.

17. Manente, V., Johansson, B., Tunestal, P., and Cannella, W., "Effects of Different Type of Gasoline Fuels on Heavy Duty Partially Premixed Combustion," SAE Int. J. Engines 2(2):71-88, 2009, doi:10.4271/2009-01-2668.

18. Cummins, L., "Diesel's Engine: From Conception to 1918," Carnot Press, 1993.

19. Clarke, J. and O'Malley, E., "Analytical Comparison of a Turbocharged Conventional Diesel and a Naturally Aspirated Compact Compression Ignition Engine Both Sized for a Highway Truck," SAE Technical Paper 201301-1736, 2013, doi:10.4271/2013-01-1736.

20. Phillips, F., Gilbert, I., Pirault, J.P., and Megel, M., "Scuderi Split Cycle Research Engine: Overview, Architecture and Operation," SAE Int. J. Engines 4(1):450-466, 2011, doi:10.4271/2011-01-0403.

21. Ricardo Advancing with Two Novel Heavy-duty Vehicle Technologies: Cryogenic Split-cycle Engine and Microwave Fuel Reforming, https://www.greencarcongress.com/2013/09/20130904 -ricardo.html, 2013.

22. Lam, N., Tuner, M., Tunestal, P., Andersson, A., Lundgren, S., and Johansson, B., "Double Compression Expansion Engine Concepts: A Path to High Efficiency," SAE Int. J. Engines 8(4):1562-1578, 2015, doi:10.4271/2015-01-1260.

23. Branyon, D. and Simpson, D., "Miller Cycle Application to the Scuderi Split Cycle Engine (by Downsizing the
Compressor Cylinder," SAE Technical Paper 2012-010419, 2012, doi:10.4271/2012-01-0419.

24. Lam, N., Andersson, A., and Tunestal, P., "Double Compression Expansion Engine Concepts: Efficiency Analysis over a Load Range," SAE Technical Paper 2018-01-0886, 2018, doi:10.4271/2018-01-0886.

25. Bhavani Shankar, V.S., Lam, N., Andersson, A., and Johansson, B., "Optimum Heat Release Rates for a Double Compression Expansion (DCEE) Engine," SAE Technical Paper 2017-01-0636, 2017, doi:10.4271/2017-01-0636.

26. Bhavani Shankar, V.S., Johansson, B., and Andersson, A., "Double Compression Expansion Engine: A Parametric Study on a High-efficiency Engine Concept," SAE Technical Paper 2018-01-0890, 2018, doi:10.4271/2018-01-0890.

27. Lam, N., Tunestal, P., and Andersson, A., "Simulation of System Brake Efficiency in a Double Compressionexpansion Engine-concept (DCEE) Based on Experimental Combustion Data," SAE paper 2019-010073, 2019, doi:10.4271/2019-01-0073.

28. Babayev, R., Houidi, M. Ben, Andersson, A., and Johansson, B., "Isobaric Combustion: A Potential Path to High Efficiency, in Combination with the Double Compression Expansion Engine (DCEE) Concept," SAE Technical Paper 2019-01-0085, 2019, doi:10.4271/2019-01-0085.

29. Babayev, R., Houidi, M. Ben, Shankar, V., Shankar, B., and Johansson, B., "Injection Strategies for the Isobaric Combustion," SAE Technical Paper 2019-01-2267, 2019.

30. Okamoto, T. and Uchida, N., "New Concept for Overcoming the Trade-Off between Thermal Efficiency, Each Loss and Exhaust Emissions in a Heavy Duty Diesel Engine," SAE Int. J. Engines 9(2), 2016, doi:10.4271/2016-01-0729.

31. Nyrenstedt, G., AlRamadan, A., Tang, Q., Badra, J., Cenker, E., Houidi, M.B., et al., "Isobaric Combustion for High Efficiency and Low Emissions in an Optical Engine," submitted to SAE WCX 2020, Detroit, USA, 21 23 April, 2020.

32. Tang, Q., Sampath, R., Sharma, P., Nyrenstedt, G., AIRamadan, A., et al., "Optical Study on the Fuel Spray Characterisitics of the Four-consecutive-injection Strategy used in High-pressure Isobaric Combustion," submitted to SAE WCX 2020, Detroit, USA, 21-23 April, 2020.

\section{Contact Information}

Harsh Goyal, Post-doctoral Fellow

Clean Combustion Research Centre (CCRC)

King Abdullah University of Science and

Technology (KAUST)

Building 5, 4216-WS11, Thuwal 23955-6900

Saudi Arabia

harsh.goyal@kaust.edu.sa

+966545109295

Aibolat Dyuisenakhmetov, PhD Student

Clean Combustion Research Centre (CCRC)

King Abdullah University of Science and

Technology (KAUST)

Building 5, 4204-WS23, Thuwal 23955-6900 
Saudi Arabia

aibolat.dyuisenakhmetov@kaust.edu.sa

+966544512452

\section{Acknowledgments}

The paper is based upon work supported by Saudi Aramco Research and Development Center FUELCOM3 program under Master Research Agreement Number 6600024505/01. FUELCOM (Fuel Combustion for Advanced Engines) is a collaborative research undertaking between Saudi Aramco and KAUST intended to address the fundamental aspects of hydrocarbon fuel combustion in engines, and develop fuel/engine design tools suitable for advanced combustion modes.

\section{Abbreviations}

AC: alternating current

aHRR: apparent heat release rate

aTDC: after top dead center

BDC: bottom dead center

BTE: brake thermal efficiency

CAC: charge air cooler

CAD: crank angle degree

CDC: conventional diesel combustion
Cl: compression ignition

CO: carbon monoxide

$\mathrm{CO}_{2}$ : carbon dioxide

CoV: coefficient of variation

DCEE: double compression expansion engine

EGR: exhaust gas recirculation

FuelMEP: fuel mean effective pressure

GHG: greenhouse gas

HCCl: homogeneous charge compression ignition

HP: high pressure

HT: heat transfer

IMEP: indicated mean effective pressure

LP: low-pressure

LTC: low-temperature combustion

$\mathrm{NO}_{\mathbf{x}}$ : oxides of nitrogen

PCP: peak cylinder pressure

PMP: peak motoring pressure 